\section{Successful Percutaneous Retrieval of an Embolized Left Atrial Appendage Closure Device in the Left Ventricular Outflow Tract}

Yoshinari Enomoto, MD; Hidehiko Hara, MD;

Shoma Kitano, MD; Shota Saito, MD;

Hiromasa Hayama, MD; Katsushi Amemiya, MD;

Yoshiyuki Yazaki, MD; Keijiro Nakamura, MD;

Raisuke Iijima, MD; Kaoru Sugi, MD;

Masao Moroi, MD; Masato Nakamura, MD

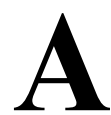

70-year-old man with a history of stroke due to persistent atrial fibrillation and intracranial hemorrhage (CHADS2 score 4, HAS-BLED score 4) was referred to undergo left atrial appendage (LAA) closure with the Watchman device (Boston Scientific Inc.). The LAA was successfully sealed with a $30-\mathrm{mm}$ Watchman and the 4 signs for correct implantation were satisfied: position, anchoring, size, and seal (Figure A). However, on the day after the procedure, the Watchman was found to have embolized into the left ventricle outflow tract (LVOT) (Figure B,C). Fortunately, the patient remained hemodynamically stable, and percutaneous retrieval was performed after sufficient informed consent. After stabilizing the device by antegrade snaring using a steerable sheath, two $25-\mathrm{mm}$ goose neck snare catheters were inserted retrogradely through $25-\mathrm{cm}$ long $16-\mathrm{Fr}$ and 8 -Fr short sheaths (Medikit Inc.) from both sides of the femoral artery. The legs and body of the Watchman were grasped and crushed with sustained traction inside the LVOT (Figure D) using the 2 snare catheters under intravenous $\beta$-blocker for longer duration of aortic valve opening. After the device was deformed small enough to be retracted from the LV into the ascending aorta, it was smoothly pulled backed inside the aorta and removed from the 16-Fr sheath without any complications (Figure E).

\section{Disclosures}

None.

Received May 20, 2021; revised manuscript received May 28, 2021; accepted May 31, 2021; J-STAGE Advance Publication released online July 2, 2021 Time for primary review: 3 days

Division of Cardiovascular Medicine, Toho University Ohashi Medical Center, Tokyo (Y.E., H. Hara, S.K., S.S., H. Hayama, K.A., Y.Y., K.N., R.I., M.M., M.N.); Division of Cardiology, Odawara Cardiovascular Hospital, Odawara (K.S.), Japan

Mailing address: Yoshinari Enomoto, MD, Division of Cardiovascular Medicine, Toho University Ohashi Medical Center, 2-22-36 Ohashi, Meguro-ku, Tokyo 153-8515, Japan. E-mail: yenomo1225@oha. toho-u.ac.jp

All rights are reserved to the Japanese Circulation Society. For permissions, please e-mail: cj@j-circ.or.jp ISSN-1346-9843

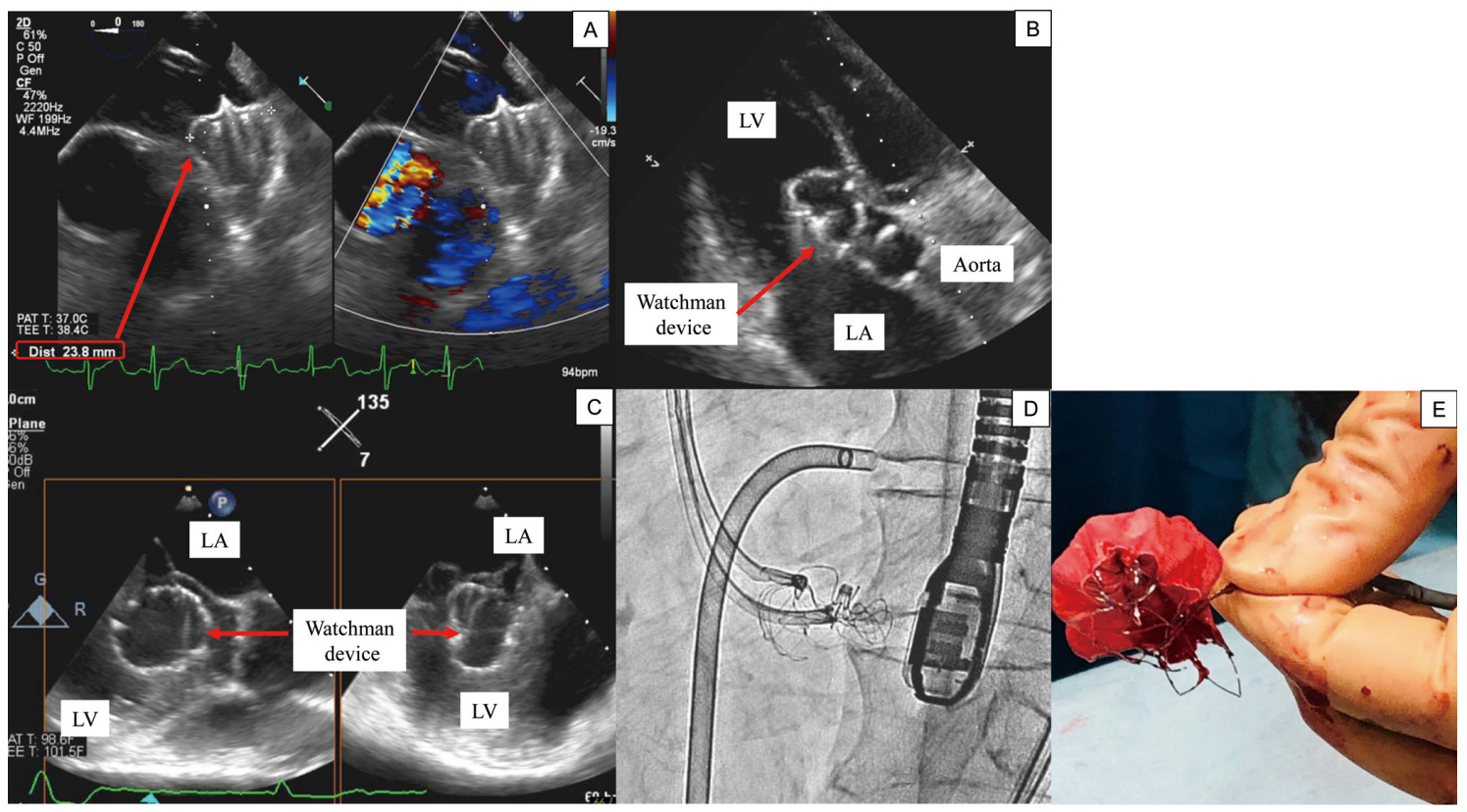

Figure. (A) Transesophageal echocardiographic (TEE) image showing the appropriate device position in the left atrial appendage with no major leakage. The measured device diameter was $23.8 \mathrm{~mm}$ (compression rate $20.7 \%$ ). (B,C) Transthoracic echocardiographic and TEE images showing the Watchman dislodged into the LV outflow tract. (D) Using goose neck snare catheters, the Watchman is grasped and crushed. (E) The Watchman outside the body immediately after retrieval. 